\title{
200 U vs. 300 U Botulinum Toxin a Injections for Patients with Neurogenic Detrusor Overactivity Secondary to Spinal Cord Injury
}

\author{
Lin JM${ }^{1,2}$, Chen Hui ${ }^{1 *}$, Liu QL ${ }^{1}$, Huang MP1 ${ }^{1}$ Li QQ ${ }^{1}$, Huang TH${ }^{1}$ and Yang XY' \\ ${ }^{1}$ Department of Urology in Guangdong Provincial Work Injury Rehabilitation Hospital, Guangdong, China \\ ${ }^{2}$ Departments of Emergency, The Eighth Hospital of Guangzhou, Guangdong, China
}

"Correspondence: Chen Hui, Department of Urology, Guangdong Provincial Work Injury Rehabilitation Hospital and Jinan University, Guangzhou-510440, China, Tel: +8613611413588; E-mail: doc.chenhui@163.com

\begin{abstract}
Objective: To evaluate the d the safety and efficacy of $200 \mathrm{U}$ vs. $300 \mathrm{U}$ botulinum toxin A (BTX-A) injections for patients with neurogenic detrusor overactivity (NDO) secondary to spinal cord injury (SCI).

Methods: We retrieved the data for the patients who receive a single dose into the detrusor of BTX-A (300 U or $200 \mathrm{U})$. The clinical outcome included maximum detrusor pressure ( $\left.P_{\text {detmax }}\right)$ during cystometry, voiding volume, urinary incontinence (UI) episodes between CICs per 24 hour, and complete dryness. Related adverse events were recorded.
\end{abstract}

Results: From July 2015 to June 2017, 28 cases received 300 U BTX-A injections (experiment group) while 19 cases received 200U BTX-A injections (control group). There were no significant differences in baseline evaluation items (gender, age, duration of spinal cord injury, level of neurological injury, AIS scores) between the two groups. There were significant improvement in Pdetmax, UI and I-QoL from baseline in the two groups. Patients in experiment group had statistically greater improvement than those in the control group for $\mathrm{P}_{\text {detmax }}\left(-32.09 \mathrm{~cm} \mathrm{H}_{2} \mathrm{O}\right.$ vs. $-\mathbf{2 8 . 0 2}$ $\left.\mathrm{cm} \mathrm{H}_{2} \mathrm{O}, \mathrm{P}=0.016\right)$, mean urinary incontinence episodes $(-6.18 / \mathrm{d} v s .-5.01 / \mathrm{d}, \mathrm{P}=0.042)$, complete dryness (11 vs. 2 , $\mathrm{P}=\mathbf{0 . 0 3 1})$, mean voiding volume (160.52 $\mathrm{ml} v s .133 .66 \mathrm{ml}, \mathrm{P}<0.001)$, and $\mathrm{I}-\mathrm{QoL}(28.53$ vs. 20.41, $\mathrm{P}<0.001)$.

Conclusion: Preliminary results indicate that 300 U BTX-A is more effective than 200 U BTX-A for SCI patients with NDO.

Keywords: Botulinum toxin A; 200U; 300U; Neurogenic detrusor overactivity; Spinal cord injury

Received Date: June 18, 2019; Accepted Date: July 01, 2019; Published Date: July 08, 2019

Citation: Chen Hui, 200 U vs. 300 U Botulinum Toxin a Injections for Patients with Neurogenic Detrusor Overactivity Secondary to Spinal Cord Injury. J Clin Cases Rep 3(1): 1-4.

(C) 2019 Tridha Scholars 
http://www.tridhascholars.org | January-2020

\section{Introduction}

Detrusor overactivity (DO) is characterized by spontaneous or provoked involuntary detrusor contractions during storage phase in urodynamic investigation [1]. Neurogenic detrusor overactivity (NDO) is DO caused by various neurogenic diseases such as multiple sclerosis (MS), stroke and spinal cord injury (SCI) [2]. NDO can cause a variety of long-term complications such as urinary incontinence, stones, hydronephrosis, recurrent urinary tract infection, vesicoureteric reflux (VUR); the most dangerous being damage of renal function. These complications may dramatically impact the quality of life of people with SCI, including limiting their behavior, causing social embarrassment, and possibly threatening their life [3].

Botulinum toxin A (Botox ${ }^{\circledR}$, Allergan, Irvine, California) is an acetylcholine release inhibitor and a neuromuscular blocking agent indicated by the beneficial treatment effect on NDO patients who have an inadequate response to or are intolerant to anticholinergic medication according to both clinical and urodynamic test, such as improvement percentage of I-QoL, reduction of urinary incontinence episodes and lower detrusor pressure, etc. [4].

To our knowledge, several studies reported satisfactory clinical results about different dose BTX-A injections. However, most of these studies were small and single-center experience. Therefore, the objective of this study was to evaluate the clinical results of 200U and 300U BTX-A injections for NDO.

\section{Method}

From July 2015 to June 2017, in patients with SCI and urodynamic DO were included. The inclusion criteria were: (1) Age $>18$ years; (2) Patients who have an inadequate response to or are intolerant of an anticholinergic medication. Exclusion criteria included patients with: (1) Acute urinary tract infections; (2) Patients or caregivers who were unable to perform CIC. Previously, the protocol was approved by hospital ethics committee. All patients provided their written consent before undergoing treatment. Bladder diaries, urodynamic test, and I-QoL were pre-formed at baseline and 12 weeks post injections.

Injections were performed with no anesthesia or under epidural anesthesia in the operating room with a $21 \mathrm{~F}$ rigid cystoscope (Ackermann). The bladder was instilled with $100-150 \mathrm{ml}$ sterile saline to achieve adequate visualization so as to avoiding the blood vessels during injections. A 23 gauge needle (Cook Urological Incorporated) was inserted approximately $2 \mathrm{~mm}$ into the detrusor. In experiment group $300 \mathrm{U}^{\text {Botox }}{ }^{\circledR}$ vials (100 U each) were reconstituted in a total of $30 \mathrm{ml}$ sterile saline $(10 \mathrm{U} / \mathrm{ml})$. In control group $200 \mathrm{U}$ BTX-A were reconstituted in a total of $30 \mathrm{ml}$ sterile saline $(6.7 \mathrm{U} / \mathrm{ml})$. A total of 30 injections were administered and distributed about $1 \mathrm{~cm}$ apart across the bladder wall [5]. The clinical outcome included maximum detrusor pressure $\left(\mathrm{P}_{\mathrm{detmax}}\right)$ during cystometry, voiding volume, urinary incontinence (UI) episodes between CICs per 24 hour, and complete dryness. Related adverse events were recorded. Statistical analysis was performed using the SPSS 13.0 soft-ware package (SPSS, Inc., Chicago, IL). Statistical relationships between pre- and postoperative outcome parameters were sought by the Student's t-test for quantitative variables. Statistical significance was considered at $\mathrm{P}$ value $<0.05$.

\section{Results}

A total of 47 SCI patients (28 cases in the experimental group and 19 cases in the control group) completed 12 weeks of follow-up and data were available and analyzed. At baseline, there were no significant differences between group with respect to any demographic or baseline characteristics (Table 1). 


\begin{tabular}{|l|c|c|}
\hline Characteristic & Experimental group $(\mathbf{n}=\mathbf{2 8})$ & Control group $(\mathbf{n}=\mathbf{~ 1 9})$ \\
\hline Age, $\mathrm{yr}$, mean $(\mathrm{SD})$ & $32.12(9.28)$ & $31.22(10.03)$ \\
\hline Gender, men, $\mathrm{n}$ & 20 & 16 \\
\hline Weight, kg, mean (SD) & $60.11(22.67)$ & $60.59(21.33)$ \\
\hline Duration of spinal cord injury, months, mean (SD) & $28.11(10.18)$ & $26.06(11.02)$ \\
\hline${ }^{2}$ Episodes of urinary incontinence, n/d, mean (SD) & $9.22(3.14)$ & $8.93(3.31)$ \\
\hline Level of SCI injury, C6-C8/ T1-T12, $\mathrm{n}$ & $3 / 25$ & $1 / 18$ \\
\hline AIS grade, A/B/C, $\mathrm{n}$ & $20 / 7 / 1$ & $16 / 1 / 1$ \\
\hline Prior anticholinergic drugs use, $\mathrm{n}$ & 28 & 19 \\
\hline Prior CIC use, $\mathrm{n}$ & 28 & 19 \\
\hline $\begin{array}{l}\text { AIS= The American Social Injury Association; SD } \\
\text { Intermittent Catheterization. } \\
\text { aThe variable was assessed from the patients' 7-day bladder diary. }\end{array}$ \\
\hline
\end{tabular}

Table 1: Baseline characteristics of the participants.

Patients in experiment group had statistically greater improvement than those in the control group for $\mathrm{P}_{\text {detmax }}\left(-32.09 \mathrm{~cm} \mathrm{H}_{2} \mathrm{O}\right.$ vs. $\left.-28.02 \mathrm{~cm} \mathrm{H}_{2} \mathrm{O}, \mathrm{P}=0.016\right)$, mean urinary incontinence episodes (-6.18/d vs. $\left.-5.01 / \mathrm{d}, \mathrm{P}=0.042\right)$, complete dryness $(11 v s$. 2, $\mathrm{P}=0.031)$, mean voiding volume (160.52 ml vs. $133.66 \mathrm{ml}, \mathrm{P}<0.001)$, and I-QoL (28.53 vs. 20.41, $\mathrm{P}<0.001)$ (Table 2).

\begin{tabular}{|c|c|c|c|}
\hline Outcome & $\begin{array}{c}\text { Experimental group } \\
n=28\end{array}$ & $\begin{array}{c}\text { Control group } \\
n=19\end{array}$ & P Value \\
\hline \multicolumn{4}{|c|}{$\mathrm{P}_{\text {detmax }}, \mathrm{cmH}_{2} \mathrm{O}$, mean $(\mathrm{SD})$} \\
\hline Baseline & $60.11 \pm 15.34$ & $61.83 \pm 16.22$ & 0.524 \\
\hline Week 12 & $-32.09 \pm 22.27$ & $-28.02 \pm 15.18$ & 0.016 \\
\hline \multicolumn{4}{|c|}{ UI, n/d, mean (SD) } \\
\hline Baseline & $9.22 \pm 3.14$ & $8.93 \pm 3.31$ & 0.864 \\
\hline Week 12 & $-6.18 \pm 2.61$ & $-5.01 \pm 1.96$ & 0.042 \\
\hline \multicolumn{4}{|c|}{ Patients with complete dryness, $\mathrm{n}$} \\
\hline Baseline & 0 & 0 & NS \\
\hline Week 12 & 11 & 2 & 0.031 \\
\hline \multicolumn{4}{|c|}{ Voiding volume, ml, mean (SD) } \\
\hline Baseline & $180.43 \pm 62.18$ & $186.74 \pm 59.04$ & 0.473 \\
\hline Week 12 & $160.52 \pm 78.05$ & $133.66 \pm 52.94$ & $<0.001$ \\
\hline \multicolumn{4}{|c|}{ I-QoL, mean (SD) } \\
\hline Baseline & $32.44 \pm 9.29$ & $33.73 \pm 9.13$ & 0.813 \\
\hline Week 12 & $28.53 \pm 14.33$ & $20.41 \pm 11.18$ & $<0.001$ \\
\hline
\end{tabular}

Table 2: Mean baseline and change from baseline in clinical outcomes.

Note: No related adverse events were recorded.

\section{Discussion}

The primary aim in the treatment of NDO is to keep the detrusor pressure within safe limits during both the filling phase and the voiding phase for protection of the upper urinary tract [2]. The present trial reports significant improvements in these parameters were evident with the $200 \mathrm{U}$ or $300 \mathrm{U}$ dose of BTX-A injection. In this trial, $300 \mathrm{U}$ BTX-A injections were superior to those $200 \mathrm{U}$ with respect to NDO. Specifically, and most importantly, the $\mathrm{P}_{\mathrm{detmax}}$ decreased more significantly of $300 \mathrm{U}$ rather than $200 \mathrm{U}$ to levels traditionally considered safe for the upper urinary tract.

Another important aims in the treatment of NDO is to improve the patient's quality of life (QoL) [2]. The improvements in urodynamic outcomes also transfer into the increases in scores of I-QoL in both groups. Significant benefits were evident by 
http://www.tridhascholars.org | January-2020

week 12. However, the mean change of I-QoL in the experiment group was substantially higher than that in control group at week 12 (28.53 vs.20.41, $\mathrm{P}<0.001)$. The larger improvement in I-QoL in the experimental group may be related to the following changes: (1) The proportional reduction of daily urinary incontinence episodes was significantly larger with $300 \mathrm{U}$ BTX-A injections than $200 \mathrm{U}$; (2) the patients in the experiment group showed greater improvement in voiding volume than those in the control group (160.52 $\mathrm{ml}$ vs. $133.66 \mathrm{ml}, \mathrm{P}<0.001)$; and (3) most importantly, 11 patients in experiment group developed complete dryness postoperatively, and their I-QoL was very high. Thus, these patients are less likely to worry about the disturbance from urinary incontinence which affects their physical activities, social relationships, and feelings.

No patients developed systemic or significant adverse events of treatment in this trial. Similar safe outcomes have also been demonstrated by previous studies at 1.5 months - 3 months [6].

A limitation of this study is that number of patients was relatively fewer. Therefore, further studies are warranted.

\section{Acknowledgement}

This study was supported by Medical Scientific Research Foundation of Guangdong Province, China (Grant Number B2017040, A2018124).

\section{References}

1. Abrams P, Cardozo L, Fall M, et al. (2002) The standardisation of terminology of lower urinary tract function: report from the standardisation sub-committee of the International continence society. Neurourology and Urodynamics 21(2): 167178.

2. Groen J, Pannek J, Diaz DC, et al. (2016) Summary of European association of urology (EAU) guidelines on neurourology. European Urology 69(2): 324-333.

3. Hagen EM, Eide GE, Rekand T, et al. [2010] Traumatic spinal cord injury and concomitant brain injury: a cohort study. Acta Neurologica Scandinavica 122(190): 51-57.

4. Chapple C, Patel A (2006) Botulinum toxin: new mechanisms, new therapeutic directions?. European Urology 49(4): 606608.

5. Schurch B, Stöhrer M, Kramer G, et al. (2000) Botulinum-A toxin for treating detrusor hyperreflexia in spinal cord injured patients: a new alternative to anticholinergic drugs? Preliminary results. The Journal of Urology 164(3 Part 1): 692-697.

6. Patel AK, Patterson JM, Chapple CR (2006) Botulinum toxin injections for neurogenic and idiopathic detrusor overactivity: a critical analysis of results. European Urology 50(4): 684-710. 